'ФГБОУ ВО Российский государственный социальный университет, Москва, Россия

ФГБУ «Национальный медицинский исследовательский центр эндокринологии» Минздрава России, Москва, Россия

${ }^{3}$ ФГБОУ ВО Юго-Западный государственный университет, Курск, Россия

${ }^{4}$ ФГБОУ ВО "Московский государственный технический университет имени Н.Э. Баумана (национальный исследовательский университет)", Москва, Россия

${ }^{5}$ ФГБОУ ВО "Московский государственный университет имени М.В. Ломоносова", Москва, Россия

${ }^{6}$ ФГОБУ ВПО Финансовый университет при Правительстве Российской Федерации, Москва Россия

Цель статьи - осветить социальные аспекты стресса как синдрома адаптации к современной ситуации в российском обществе для обоснования правомерности рассмотрения общества в качестве фактора, способствующего развитию и распространению избыточной массы тела и ожирения среди российского населения.

Поднимается проблема условий и качества повседневной жизни значительной части населения нашей страны, которые сопровождаются повышенной стрессогенностью повседневных жизненных событий. Современное российское общество, обладая имманентно-присущим ему системным качеством - свойством стрессогенности, в сочетании со спецификой гиподинамичного образа жизни, является мощным и системно действующим фактором, провоцирующим развитие и распространение среди россиян ожирения и избыточной массы тела. Анализируются стрессогенные факторы современного общества, порождаемые неупорядоченностью и некомплементарностью работы социальных институтов, нестабильностью в экономической и политической сферах. Исследуются пищевые семейные традиции, парадигма питания, досуговая активность россиян. Обсуждается нерациональность использования человечеством продуктов питания. Предложены мероприятия по противодействию и профилактике ожирения.

КЛЮЧЕВЫЕ СЛОВА: российское общество, стрессогенный фактор ожирения, стресс, ожирение, избыточная масса тела, ситуация, способствующая ожирению, медицинские и социальные проблемы ожирения.

\title{
OBESITY IN RUSSIA: MODERN VIEW IN THE LIGHT OF A SOCIAL PROBLEMS
}

(C) Irina V. Leskova ${ }^{1 *}$, Ekaterina V. Ershova², Elena A. Nikitina ${ }^{3}$, Vladimir Ya. Krasnikovsky4, Yuliya A. Ershova5 , L V. Adamskaya ${ }^{6}$

${ }^{1}$ Russian State Social University, Moscow, Russia

${ }^{2}$ Endocrinology Research centre, Moscow, Russia

${ }^{3}$ Southwest State University, Kursk, Russia

${ }^{4}$ Bauman Moscow State Technical University, Moscow, Russia

${ }^{5}$ Lomonosov Moscow State University, Moscow, Russia

${ }^{6}$ Finance University under the Government of the Russian Federation, Moscow, Russia

The purpose of the article is to highlight the social aspects of stress as a syndrome of adaptation to the current situation in Russian society in order to justify the consideration of society as a factor contributing to the development and spread of overweight and obesity among the Russian population.

The problem of the conditions and quality of everyday life of a significant part of the population of our country is raised, which are accompanied by an increased stress level of everyday life events. A modern Russian society, possessing an immanently inherent systemic quality - a stress-stress property, combined with the specificity of a hypodynamic lifestyle, is a powerful and systemically active factor that provokes the development and spread of obesity and overweight. The stress factors of modern society, generated by the disorder and non-complementarity of the work of social institutions, instability in the economic and political spheres are analyzed. Food family traditions, food paradigm, leisure activity of Russians are studied. The irrationality of the use of food by mankind is discussed. The proposed measures to combat and prevent obesity.

KEYWORDS: Russian society, stressful obesity factor, stress, obesity, extra weight, the obesity causing situation, medical and social obesity questions

\section{ВВЕДЕНИЕ}

В наши дни распространенность ожирения представляет собой серьезную проблему, которую Всемирная организация здравоохранения (ВО3) сочла возможным возвести в «ранг» неинфекционной эпидемии
XXI в. (соответствующее решение ВОЗ было принято еще в 1997 г.). В настоящее время в мире около 671 млн человек на планете имеют ожирение, половина из них проживают в 10 странах: США, Российской Федерации, Китае, Индии, Бразилии, Мексике, Египте, Германии, Пакистане и Индонезии [1]. Согласно данным статисти- 
ки [2], в США более половины населения имеют индекс массы тела (ИМТ), превышающий норму, в Великобритании - 51\%, в Германии - 50\%, в Китае и Японии ИМТ превышает норму у $15 \%$ и 16\% населения соответственно, хотя там избыточный вес и ожирение встречаются гораздо реже, чем в других странах. В России, по данным разных авторов, распространенность ожирения и избыточной массы тела среди взрослого населения составляет от 20,5 до 54\% [3-4], по оценкам экспертов ВО3, на 2016 г. ожирением страдают около 23,1\% населения в возрасте старше 18 лет [5]. Наблюдается и существенное увеличение распространенности ожирения не только среди взрослого населения, но и в популяции детей и подростков: за последнее двадцатилетие доля страдающих этим недугом в возрастной группе 6-11-летних увеличилась с 7 до 13\%, в группе 12-19-летних возросла с 5 до 14\%, ожирение выявлено у 5,5\% сельских и 8,5\% городских детей [6-8]. По оценке ВО3, в 2014 г. около 41 млн детей в возрасте до 5 лет имели избыточный вес или ожирение. В Африке число детей с избыточным весом или ожирением выросло почти вдвое - с 5,4 млн человек в 1990 г. до 10,6 млн в 2014 г. При этом в 2014 г. почти половина детей в возрасте до 5 лет с избыточным весом или ожирением проживали в Азии [8].

Согласно мнению экспертов ВО3, «в современном обществе дети и молодежь подвергаются множеству факторов, способных оказывать влияние на развитие ожирения. Снижение двигательной активности в сочетании с нарушением режима питания и неправильным образом жизни приводит к появлению избыточной массы тела за счет отложения жира в тканях. Ожирение является одной из важных проблем современной медицины. Его частота увеличивается, и в развитых странах ожирение приобретает масштабы социально значимой патологии» [9]. Как известно, ожирение приводит не только к снижению общей продолжительности жизни, но и к инвалидности людей, в том числе молодого возраста, из-за частого развития тяжелых коморбидных заболеваний. Повышенный ИМТ является одним из основных факторов риска таких неинфекционных заболеваний, как артериальная гипертензия, ишемическая болезнь сердца, сахарный диабет 2 типа, нарушения опорно-двигательной системы, некоторых онкологических заболеваний (в т.ч. рака эндометрия, молочной железы, яичника, предстательной железы, печени, желчного пузыря, почки и толстой кишки). Риск этих неинфекционных заболеваний возрастает по мере увеличения ИМТ. Рост распространенности ожирения сопровождается и повышением смертности от сопутствующих ожирению заболеваний. Исходя из данных, опубликованных Всемирным банком и ВО3, ежегодно около 3,4 млн взрослого населения умирают вследствие излишнего веса и ожирения [9-10].

Проблемы ожирения и избыточного веса имеют не только медицинские и психологические, но и социальные и экономические последствия, связанные с увеличением расходов на здравоохранение и снижением работоспособности, эффективности труда людей и уровня их доходов [7]. Кроме этого, ожирение способно порождать социальные и экономические последствия, провоцируя патологические состояния, которые определяют копулятивную и репродуктивную несостоятельность мужчин молодого возраста (до 60\% соответствую- щихпатологических состояний) и осложняют реализацию детородной функции у женщин, имеющих излишний вес [11-13]. Социально-экономические проблемы, порожденные ожирением, проявляются и на макроуровне, где приобретают не только культурологическую, но и политическую окраску. Как отмечает С.А. Кравченко, ускорение движения социума по все более усложняющимся траекториям социального и культурного развития «... затрагивает функционирование жизненных ценностей, включая характер питания человека. Процессы индустриализации, рационализации и глобализации питания имеют амбивалентные последствия для современного человека: с одной стороны, потребление продуктов выходит из локально-культурного, сезонного и климатического контекста, осуществляется более эффективно и с меньшими затратами времени, контролируется их качество и калорийность, а с другой - рефлексия людей в отношении потребления пищи все более манипулируется глобальным агробизнесом, преследующим прагматические интересы увеличения прибыли посредством навязывания космополитической еды и соответствующего вкуса, что порождает новые проявления дегуманизации, отчуждения, культурно обусловленные болезни (анорексия, ожирение, диабет и др.)» [14].

Существующая в обществе явная стигматизация по весу представляет собой очевидную социальную проблему, с которой сталкиваются люди с ожирением. Они зачастую воспринимаются окружающими как менее симпатичные, ленивые, слабохарактерные, с низким социальным статусом, сексуально непривлекательные. Не секрет, что женщина с избыточным весом тратит гораздо больше времени на поиск партнера, а замужние женщины в среднем весят больше незамужних того же возраста. Распространение эпидемии ожирения сопровождалось поворотом стандартов красоты в сторону худых и спортивных людей, что легко обнаружить, сравнив современные обложки глянцевых журналов с образцами 50-60-х годов XX в.

Стигматизация касается не только брачно-сексуальных отношений, но проявляется и в поиске работы: люди с ожирением воспринимаются менее интеллектуальными и в перспективе менее успешными в карьерном отношении. Тучный мужчина зарабатывает в среднем на 5\% меньше, толстая женщина - на 12\%. Дискриминируют полных людей компании, которые имеют определенные требования к внешности персонала, например, представители ресторанного, модельного бизнеса, сферы услуг. Считается, что у толстых кандидатов "хуже выражены деловые и личные компетенции", раз они не могут "привести себя в порядок" [14].

Предвзятое отношение окружающих, даже будучи абсолютно иррациональным, является одной из причин срыва в выполнении диетических ограничений, поскольку эмоциональный дискомфорт обуславливает потребность возместить «страдания» доступным поощрением, т.е. «заеданием» стрессов.

\section{СТРЕССОГЕННЫЕ ФАКТОРЫ СОВРЕМЕННОГО ОБЩЕСТВА}

Говоря о стрессогенности жизни вообще и в России в частности, сосредоточим внимание в контексте 
рассматриваемой проблематики на российском обществе, где стресс сопровождает обыкновенных граждан в их повседневной жизни повсюду при решении задач в социальной, экономической, правовой, правоприменительной сферах жизни [15-16].

Особо отметим, что современное российское общество находится в переходном периоде своего развития. Неупорядоченность, некомплементарность работы его различных социальных институтов, нестабильность в экономической сфере - проблемы, многие из которых решаются за счет обычных рядовых граждан. Это происходит на фоне перевода нашего общества и всех его граждан на стопроцентные условия рыночного существования без учета реальной готовности людей к этому процессу. По нашему мнению [15-16], в стране соответствующие условия для такого перехода еще не сформированы, значительная часть наших соотечественников попросту не готовы к полноценному принятию рыночных отношений и эффективному функционированию в их режиме. Практически половина наших сограждан в своем повседневном бытовании являются приверженцами государственного патернализма (от лат. paternus «отцовский, отеческий» - система отношений, при которой власти обеспечивают потребности граждан, которые в обмен на это позволяют диктовать им модели поведения, как публичного, так и частного), обладают недостаточной финансовой грамотностью в экономическом и правовом отношениях, излишне и необоснованно доверчивы при взаимодействии с различными государственными и негосударственными финансовыми институтами и организациями, склонны проявлять экономическую безответственность в отношении своей жизни и жизни своих семей.

Факт вполне закономерен: десятки миллионов сегодняшних россиян - люди, которых на протяжении 70 с лишним лет советской власти формировали для жизни и деятельности в условиях социальной стабильности, плановой экономики, тотального государственного патернализма и иллюзии всеобщего единообразия. Внезапно (по историческим меркам) и без какой-либо адекватной подготовки, фактически - по указанию «сверху», этих людей «бросили» в неопределенность квазирыночных отношений, по мере развития которых регулярно меняются «правила игры» в экономической, социальной и политической сферах. В масштабах общества данная ситуация создает условия повышенной стрессогенности для множества россиян, что фиксируется данными общероссийских опросов [17].

Дискомфорт, фрустрации, чувство генерализованной тревожности и не самое лучшее социальное самочувствие - все это есть стрессогенные факторы либо проявления результатов влияния стресса (например, тревожность), действующие на наших соотечественников на разных уровнях: личностном, предметно-ситуационном, социально-психологическом или социальном.

\section{ПАРАДИГМА ПИТАНИЯ, ПИЩЕВЫЕ ТРАДИЦИИ, ДОСУГ}

Россияне в 1990-е годы полнели из-за резких изменений во всех сферах жизни, падения ее уровня, стремительного роста безработицы и бедности, дополнительных стрессов и неопределенности [18]. В этот период изменились сама парадигма питания и семейные пищевые традиции, стал иным такой важный фактор здоровья, как рацион питания, появились доступные и дешевые продукты, полуфабрикаты, ослаб родительский контроль над питанием детей, повысилась доступность нездоровой еды для школьников. У подростков появилась привычка утолять жажду сладкими газированными напитками и соками. Кроме того, на рост эпидемии ожирения среди детей и, соответственно, взрослых повлиял и тот факт, что в стрессогенные 1990-е годы матери, вынужденные работать, стали чаще переводить грудных детей на искусственные смеси. Ни для кого не секрет, что именно грудное вскармливание является самой лучшей профилактикой ожирения и ассоциированных с ним заболеваний.

Другим немаловажным фактором роста ожирения является нехватка физической активности. То, что жизнь большинства россиян, особенно живущих в городах, гиподинамична и не изобилует физической активностью, факт общеизвестный.

Интерес представляют данные о структуре досуговой активности россиян [19].

Направленность досуговой активности, то есть содержательная сторона наполнения свободного времени, является важным типологизирующим фактором, определяющим специфику и качество свободного времени той или иной социальной группы, слоя. Можно выделить три основных типа реальной досуговой активности:

- простые (домашние) формы проведения досуга («простой досуг»);

- традиционные формы проведения досуга («традиционный досуг»);

активные внедомашние формы проведения досуга («активный досуг»).

Кратко охарактеризуем их.

Простой досуг. Это самые распространенные и не требующие от самого человека каких-либо дополнительных затрат домашние формы проведения свободного времени (например, просмотр телепередач, прослушивание радиопередач, занятие домашним хозяйством или «просто отдых», не предполагающий необходимости что-либо делать вообще). При отсутствии любой досуговой активности вне дома они представляют собой самый «простой» тип досуговой активности.

Добавление к этим домашним «развлечениям» тех или иных увлечений, включая чтение периодики, книг, прослушивание музыки, занятия компьютером и другие хобби, более активное общение, направленное на пребывание вне семьи, встречи с друзьями, посещение храма, обогащает свободное время и несет в себе более определенный развивающий компонент. Оставаясь домашним по своей сути, такой тип досуга более разнообразен и интересен, чем простое «сидение» перед телевизором и домашние хлопоты, и в целом является наиболее «традиционным» для России, поскольку именно его практикуют подавляющее большинство.

Таким образом, та часть населения, которая использует только простые или традиционные формы заполнения свободного времени, не проявляет активного социального и культурного участия вне дома, являющегося признаком полноценности и разносторонности досуга и важным условием высокого качества жизни. Актив- 
ный досуг, о котором идет речь как о важнейшем показателе качества жизни, начинается только при условии расширения спектра досуговых предпочтений за счет внедомашних видов культурной, развлекательной, рекреационной, общественной или иной деятельности, дополнительного образования и т. д.

Здесь можно выделить три подтипа досуга. Первый предполагает дополнение традиционных досуговых форм такими «легкими жанрами», как развлечения и спорт - посещение дискотек и ночных клубов, кафе и баров, а также кружков и клубов по интересам, спортивных залов и т.п. Второй, также не исключая традиционные жанры, включает в себя еще элементы саморазвития человека, его культурного и интеллектуального совершенствования - посещение в свободное время театров и концертов, музеев и выставок, а также получение дополнительного образования в той или иной сфере. Третий подвид - это досуг, требующий от человека проявления активной гражданской позиции, участия в работе различных общественных или политических организаций.

По поводу последнего типа важно отметить, что посещение кино, театров, музеев, концертов, клубов, кафе и т.п., включенность в деятельность общественно-политических институтов, любая другая социальная активность вне дома требуют заметных дополнительных затрат как материального, так и интеллектуального плана. Однако именно это и придает социальной жизни людей наибольшую полноту. Поэтому «активный» тип досуга, венчающий собой иерархическую лестницу типологии досуговой активности, наиболее богат, разнообразен и социально привлекателен [20].

Распределение россиян согласно особенностям наиболее часто практикуемых ими форм проведения свободного времени (характерных типов проведения досуга) представлено ниже [20]:

- простые (домашние) формы проведения досуга 15\%;

традиционные формы проведения досуга - 57\%:

- традиционные домашние формы проведения досуга - 14\%;

- традиционные формы проведения досуга, связанные с общением, - 43\%;

активный внедомашний досуг - 28\%:

- активный - развлечения, спорт - 9\%;

- активный - культура, саморазвитие - 16\%;

- активный - участие в работе общественных, политических организаций - 3\%.

Представленные данные убедительно показывают, насколько распространена в отечественной культуре повседневности традиция малоподвижного досугового времяпрепровождения.

Кроме этого, распространению в России ожирения и избыточной массы тела способствуют и сам образ жизни, и связанные с ним особенности питания жителей больших и средних городов, сложившиеся в последние десятилетия.

Вышеперечисленные факторы формируют предпосылки для увеличения количества лиц с избыточной массой тела, кроме того, их действие усугубляется влиянием сложившейся в российском социуме стрессогенной ситуации.

\section{МЕРОПРИЯТИЯ ПО ПРОТИВОДЕЙСТВИЮ ОЖИРЕНИЯ}

Какие же направления противодействия ожирению можно считать перспективными на сегодняшний день?

Понятно, что общенациональные проблемы лишнего веса должны решаться комплексно. И здесь существует несколько путей социально-политико-экономической направленности, в рамках которых предлагаются решения и разрабатываются мероприятия:

1) разработка, внедрение и совершенствование финансовых инструментов управления потреблением и качеством продуктов питания вообще и налоговых в частности;

2) осуществление мер политического характера, направленных на формирование здорового образа жизни населения;

3) активная пропаганда здорового питания;

4) активная пропаганда повышения уровня физической активности, здорового образа жизни среди всего населения, введение в повседневную культуру образцов поведения, предполагающих повышение двигательной активности, включая создание и внедрение моды на хорошее физическое состояние организма в среде представителей обширного множества имеющихся в обществе социальных групп;

5) ограничение на рекламу вредных пищевых продуктов;

6) рационализация в интересах общества (а не обогащения компаний) работы пищевой промышленности;

7) улучшение доступа широких масс населения к качественной еде;

8) введение ограничений на рекламу вредных пищевых продуктов;

9) разработка программ поддержки и стимулирования производства фермерскими хозяйствами натуральной и экологически чистой продукции.

Раскроем содержание некоторых из обозначенных пунктов.

Подчеркнем, что пищевая промышленность может способствовать внедрению практики здорового питания, совершенствуя свою деятельность по следующим направлениям:

- снижение содержания жира, сахара и соли в пищевых продуктах;

- обеспечение возможности выбора в пользу здоровых и питательных продуктов, в т.ч. по доступным ценам;

- проведение социально-ответственного маркетинга, особенно продуктов питания, предназначенных для детей и подростков [6].

Bсе это должно сопровождаться запрещением использования трансжиров в процессе производства продуктов питания [21].

ВО3 разработан «Глобальный план действий по профилактике неинфекционных заболеваний и борьбе с ними на 2013-2020 годы» [5], дополняющий ранее принятые Рамочную конвенцию ВОЗ по борьбе против табака и Глобальную стратегию по питанию, физической активности и здоровью. Предполагается, что его реализация будет способствовать достижению к 2025 г. ряда глобальных целей в области борьбы с неинфекционными заболеваниями, включая сокращение преждевременной смертности от них на 25\% и стабилиза- 
цию глобальных показателей по ожирению на уровне 2010 г. [22].

Сформулируем еще одну проблему современного социума - нерациональное использование человечеством продуктов питания, находящихся в его распоряжении [23-25].

В мире продукты питания производятся в таких количествах, которых вполне хватило бы для того, чтобы накормить все население нашей планеты. Однако произведенная еда распределяется крайне неравномерно как по территориям (странам и регионам), так и в социальном пространстве. Согласно данным, приводимым А.В. Терёшкиной, во всем мире сегодня ежегодно теряется или используется не по назначению около трети всех произведенных продуктов питания, или 1,3 млрд тонн в год. А это значит, что теоретически, накормить всех людей на Земле можно было бы, просто вдвое уменьшив соответствующие потери и расходы [26].

Заметим, что сегодня, особенно в странах с низким и средним уровнем экономического развития, проявляются несколько классов противоположных проблем: сосуществуют и практически синхронно обостряются проблемы, вызванные как недостаточностью питания, так и ожирением. То есть в таких государствах одна часть населения страдает от голода и болезней, сопряженных с недоеданием, а другая - от ожирения и сопутствующих ему заболеваний.

\section{ПРОФИЛАКТИКА ОЖИРЕНИЯ}

Сегодня в России профилактика ожирения осуществляется на двух уровнях [27] - индивидуальном и государственном.

Индивидуальный уровень предполагает реализацию таких мер, как:

- совершенствование рациона питания: ограничение потребления жиров, увеличение потребления овощей, фруктов и зерновых продуктов, снижение потребления сахаров;
- формирование приверженности здоровому образу жизни: повышение физической активности, следование рациональному режиму (распорядку) дня.

Государственный уровень профилактики ожирения предполагает следующее:

- использование социальной рекламы здорового образа жизни;

- развитие спортивно-физкультурной инфраструктуры и обеспечение доступности ее объектов (спортивных сооружений) для всех слоев населения;

- развитие городской инфраструктуры таким образом, чтобы она поощряла физическую активность населения (строительство пешеходных, велосипедных дорожек и другое);

- снижение налогов на производство и продажу фруктово-овощной продукции;

- повышение налогов на высококалорийные продукты.

\section{ЗАКЛЮЧЕНИЕ}

Рост распространенности ожирения требует принятия всех возможных мер для его сдерживания. Учитывая, что ожирение в 95-99\% случаев носит экзогенно-конституциональный характер, т.е. обусловлено влиянием факторов внешней среды при наследственной предрасположенности к набору веса, влияние на уровень и образ жизни населения имеет важное значение.

Государство в состоянии создать определенные условия, которые будут если не препятствовать, то хотя бы не провоцировать рост распространенности избыточного веса и ожирения среди российского населения. Но для этого необходимо иметь действенные программы и механизмы обеспечения населения продовольствием, рационализации распределения продовольствия в среде населения, формирования культуры здорового образа жизни и повышения качества жизни населения, обучения населения правильному стресс-совладающему поведению, минимизации влияния стрессорных факторов, связанных с трансформацией общественной системы.

\section{СПИСОК ЛИТЕРАТУРЫ | REFERENCES}

1. Ng M, Fleming T, Robinson $M$, et al. Global, regional, and national prevalence of overweight and obesity in children and adults during 1980-2013: a systematic analysis for the Global Burden of Disease Study 2013. Lancet. 2014;384(9945):766-781 doi: 10.1016/S0140-6736(14)60460-8

2. Ивлеева А.Ю., Бурков С.Г. Избыточный вес и ожирение - проблема медицинская, а не косметическая // Ожирение и метаболизм. 2010. - T.7. - №3. - C.15-19. [Ivleeva AYu, Burkov SG. Izbytochnyy ves i ozhirenie - problema meditsinskaya, a ne kosmeticheskaya. Ožirenie i metabolizm. 2010;7(3):15-19. (In Russ.)] doi: 10.14341/2071-8713-4978

3. Бутрова С.А. От эпидемии ожирения к эпидемии сахарного диабета // Международный эндокринологический журнал. - 2013. - №2(50). - C.19-24. [Butrova SA. Ot epidemii ozhireniya kepidemii sakharnogo diabeta. International journal of endocrinology. 2013;2(50):19-24. (In Russ.)]

4. Старостина Е.Г. Ожирение как психосоматическое заболевание // Ожирение и метаболизм. - 2005. - Т.2. - №3. - С.18-23. [Starostina EG. Ožirenie i metabolizm. 2005;2(3)18-23. (In Russ.)] doi: 10.14341/2071-8713-4848

5. Who.int [Internet]. World Health Organisation Global Health Observatory data repository. Prevalence of obesity among adults, $\mathrm{BMI} \geq 30$, age-standardized. Estimates by country. [updated 2017 Sep 22; cited 2019 Jan 28]. Available from: http://apps.who.int/gho/data/node. main.A900A?lang=en
6. Крысанова В.С., Журавлева М.В., Сереброва С.Ю. Социальная и экономическая значимость избыточной массы тела и ожирения в Российской Федерации. Основные подходы к лечению ожирения // РМЖ. - 2015. - №26. - C.1534-1537. [Krysanova VS, Zhuravleva MV, Serebrova SYu. Sotsial'naya i ekonomicheskaya znachimost' izbytochnoi massy tela i ozhireniya v Rossiiskoi Federatsii. Osnovnye podkhody k lecheniyu ozhireniya. RMŽ. 2015;(26)1534-1537. (In Russ.)]

7. Бронникова В.В., Мошков В.И. Рост ожирения: причины, экономические последствия, меры профилактики // Фундаментальные и прикладные исследования кооперативного сектора экономики. - 2017. - №2. - C.69-76. [Bronnikova WV, Moshkov VI. Growth of obesity: causes, economic consequences, measures of prevention. Fundamental'nye i prikladnye issledovaniâ kooperativnogo sektora èkonomiki. 2017;(2):69-76. (In Russ.)]

8. Популо Г.М., Сафоненко С.В. Изучение проблемы избыточной массы тела учащейся молодежи // Азимут научных исследований: педагогика и психология. - 2017. - Т.6. - №3(20). - С.195-198. [Populo GM, Safonenko SV. RESEARCH OF THE YOUTH OVERWEIGHT PROBLEM. Azimut naučnyh issledovanij: pedagogika i psihologiâ. 2017;6(3):195-198. (In Russ.)]

9. Проблема ожирения в Европейском регионе ВОЗ и стратегии ее решения / Под ред. Branca F, Nikogosian H, Lobstein T. - Копен- 
гаген: Европейское региональное бюро Всемирной организации здравоохранения, 2009. - 392 с. [Branca F, Nikogosian H, Lobstein T, editors. The challenge of obesity in the WHO European Region and the strategies for response. Copenhagen: WHO Regional Office for Europe; 2009. 392 р. (In Russ.)] [доступ от 16.03.2019]. Доступ по: http:// www.euro.who.int/ru/publications/abstracts/challenge-of-obesity-inthe-who-european-region-and-the-strategies-for-response-the

10. Ожирение: Этиология, патогенез, клинические аспекты: Руководство для врачей. / Под ред. Дедова И.И., Мельниченко Г.А. - М.: Медицинское информационное агентство, 2004. 456 c. [Dedov II, Mel'nichenko GA, editors. Ozhirenie: Etiologiya, patogenez, klinicheskie aspekty: Rukovodstvo dlya vrachei. Moscow: Meditsinskoe informatsionnoe agentstvo; 2004. 456 p. (In Russ.)]

11. Джафарова А.Г. Качество жизни женщин репродуктивного возраста с избыточной массой тела и ожирением и самооценка ими собственного здоровья. Актуальні проблеми сучасної медицини. Актуальні проблеми сучасної медицини: вісник української медичної стоматологічної академії. - 2016. - №4(56). - С.101-105. [Jafarova AG. Life quality of azerbaijanian childbearing-aged women with overweight and obesity and selfassessment of their own health Aktual'ni problemi sučasnoï medicini. 2016;(4):101-105. (In Russ.)]

12. Авдиюк Г.А., Киселева Т.В., Серякова М.В., Шоркин Ю.В. Ожирение как фактор риска репродуктивных неудач. Медицина и образование в Сибири. - 2011. - №4. [Avdiyuk GA, Kiseleva TV, Seryakova MV, Shorkin YV. Obesity as risk factor of reproductive failures Journal of Siberian medical sciences. 2011;(4). (In Russ.)]

13. Полякова М.В. Высокоэнергетические рационы молодых мужчин: угроза для мужской фертильности и репродуктивных неудач в будущем? Смоленский медицинский альманах. - 2017. - №(4). C.96-99. [Poliakova MV. High-energy diets of young men: the threat for male fertility and reproductive failures in the future? Smolenskij medicinskij al'manah. 2017;(4):96-99. (In Russ.)]

14. Кравченко С.А. Социальная и культурная динамика еды: приобретения и уязвимости // Социологические исследования. - 2015. №1(369). - C.85-94. [Kravtchenko SA. Social and cultural dynamics of food: gains and vulnerabilities. Sociologičeskie issledovaniâ. 2015:(1):85-94. (In Russ.)]

15. Лескова И.В., Мазурина Н.В., Трошина Е.А., и др. Социально-медицинские аспекты пожилого возраста: ожирение и профессиональное долгожительство // Ожирение и метаболизм. - 2017. - T.14. - №4. - C.10-15. [Leskova IV, Mazurina NV, Troshina EA, et al. Social and medical aspects of elderly age: obesity and professional longevity. Ožirenie i metabolizm. 2017;14(4):10-15. (In Russ.)] doi: 10.14341/omet2017410-15

16. Лескова И.В., Ермаков Д.Н., Матушевская Е.Г., Нишнианидзе О.О. Социально-медицинские аспекты нормализации массы тела // Ожирение и метаболизм. - 2016. - T.13. - №4 - C.49-52. [Leskova IV, Ermakov DN, Matushevskaya EG, Nishnianidze OO. Socio-medical aspects of the normalization of body mass. Ožirenie i metabolizm. 2016;13(4):49-52. (In Russ.)] doi: 10.14341/OMET2016449-52

17. wciom.ru [Интернет]. Социальное самочувствие россиян: мониторинг. Москва: Всероссийский центр изучения общественного мнения [16.11.2018; доступ от 16.03.2019]. Доступ по: https://wciom.ru/index.php?id=236\&uid=9430
18. Huffman SK, Rizov M. Determinants of obesity in transition economies: The case of Russia. Econ Hum Biol. 2007:5(3):379-391. doi: 10.1016/j.ehb.2007.07.001

19. Седова Н.Н. Динамика досуговых предпочтений россиян. В аналитическом докладе: Двадцать лет реформ глазами россиян (опыт многолетних социологических замеров). - Москва: Институт социологии РАН в сотрудничестве с Представительством Фонда имени Фридриха Эберта в Российской Федерации, 2011. - C.247-259. [Sedova NN. Dinamika dosugovykh predpochtenii rossiyan. In: Institute of Sociology of Russian Academy of Sciences, in collaboration with Friedrich Ebert Foundation presense in Russian Federation. Dvadtsat' let reform glazami rossiyan (opyt mnogoletnikh sotsiologicheskikh zamerov). Moscow; 2011. p.247-259. (In Russ.)] [доступ от 16.03.2019]. Доступ по: http://www.isras.ru/analytical_report_twenty_years_reforms.html

20. Седова Н.Н. Досуговая активность граждан // Социологические исследования. - 2009. - №12. - C.56-59. [Sedova N.N. Dosugovaya aktivnost' grazhdan. Sociologičeskie issledovaniâ. 2009;(12):56-69. (In Russ.)]

21. takzdorovo.ru [Интернет]. Takzdorovo.ru. Официальный ресурс Министерства здравоохранения Российской Федерации. Профи лактика. Образ жизни. «В России разработали меры профилактики от ожирения». [18.11.2016 года; доступ: 16.03.2019]. Доступ по: http://www.takzdorovo.ru/profilaktika/obraz-zhizni/v-rossii-razrabotali-meri-profilactiki/

22. Медведев Ж.А. Питание и долголетие. - М.: Время, 2012. - 528 с. [Medvedev ZhA. Pitanie i dolgoletie. Moscow: Vremya; 2012. p. 528. (In Russ).]

23. Колоспицына М.Г. Бердникова А.Н. Избыточный вес: сколько это стоит и что с этим делать? // Прикладная эконометрика. - 2009. №3(15). - C.72-93. [Kolospitsyna MG, Berdnikova AN. Izbytochnyi ves: skol'ko eto stoit i chto s etim delat'? Prikladnâ̂ èkonometrika. 2009;(3):72-93. (In Russ).]

24. Романцова Т.И. Эпидемия ожирения: очевидные и вероятные причины // Ожирение и метаболизм. - 2011. - Т.8. - №1. - С.5-19. [Romantsova TI. Epidemiya ozhireniya: ochevidnye i veroyatnye prichiny. Ožirenie i metabolizm. 2011;8(1):5-19 (In Russ).] doi: 10.14341/2071-8713-5186

25. Рувинский В. Карта жира. Россия страдает от лишнего веса // Коммерсантъ Деньги. - 2016. - №41. - C.11. [Ruvinskii V. Karta zhira. Rossiya stradaet ot lishnego vesa. Kommersant" 2016;(41):11 (In Russ).] [15.10.2016; доступ: 22.04.2018]. Доступ по: https://obzor. press/coffee-news/32895

26. Терешкина А.В. Мировые приоритеты политики в области питания // Контентус. - 2016. - №3(44). - C.10-13. [Tereshkina A.V. Mirovye prioritety politiki v oblasti pitaniya. Kontentus. 2016;3(44):10-13 (In Russ).]

27. Тажибаев Ш.С., Балгимбеков Ш.А., Кайнарбаева М.С. Здоровое питание - основа профилактики избыточной массы тела и ожирения (Модуль 1). - Алматы: Казахская Академия питания, 2012. - 32 c. [Tazhibaev ShS, Balgimbekov ShA, Kainarbaeva MS. Zdorovoe pitanie - osnova profilaktiki izbytochnoi massy tela i ozhireniya (Modul' 1). Almaty: Kazakh Academy of Nutrition; 2012 32 p. (In Russ).]

\section{ИНФОРМАЦИЯ ОБ АВТОРАХ [AUTHORS INFO]}

*Лескова Ирина Валерьевна, д.м.н., профессор [Irina V. Leskova, ScD in sociology, professor]; адрес: 129226, г. Москва, ул. Вильгельма Пика, д. 4 стр. 1 [address: 4/1 Vil'gel'ma Pika street, 129226 Moscow, Russia]; ORCID: https://orcid.org/0000-0001-6083-6692; eLibrary SPIN: 9055-9671; e-mail: leskova.i@yandex.ru

Ершова Екатерина Владимировна, к.м.н. [Ekaterina V. Ershova, MD, PhD]. ORCID: https://orcid.org/0000-0002-6220-4397; eLibrary SPIN: 6728-3764; e-mail: yu99pol06@rambler.ru Никитина Елена Александровна, кандидат психологических наук [Elena A. Nikitina, PhD in psychology)]; eLibrary SPIN:7846-8674; e-mail: eanikitina72@mail.ru

Красниковский Владимир Ярославович, кандидат экономических наук [Vladimir Ya. Krasnikovsky, PhD in economics]; eLibrary SPIN: 4258-1979; e-mail: eanikitina72@mail.ru

Ершова Юлия Андреевна, студент [Yuliya A. Ershova, student]; eLibrary SPIN: 5412-0636; e-mail: ershic1999@yandex.ru. Адамская Любовь Владимировна, кандидат социологических наук [Lyubov V. Adamskaya, PhD in sociological sciences]; eLibrary SPIN: 2793-2897; e-mail: adamskaia@yandex.ru 


\section{ЦИТИРОВАТЬ:}

Лескова И.В., Ершова Е.В., Никитина Е.А., Красниковский В.Я., Ершова Ю.А., Адамская Л.В. Ожирение в России: современный взгляд под углом социальных проблем // Ожирение и метаболизм. — 2019. — Т.16. — №1. — С. $20-26$. doi: $10.14341 /$ omet9988

\section{TO CITE THIS ARTICLE:}

Leskova IV, Ershova EV, Nikitina EA, Krasnikovskiy VY, Ershova YuA, Adamskaya LV. Obesity in Russia: modern view in the light of a social problems. Obesity and metabolism. 2019;16(1):20-26. doi:10.14341/omet9988 